\title{
Linguistics in Fashion: Explaining Concepts with Visual Metaphors
}

\author{
S. Sonina \\ University of Toronto Scarborough
}

\begin{abstract}
This empirical project, a study of the effect of metaphors and games on the learning process, is related to my research on fashion terminology but focuses on student-professor or student-computer interactions. The project emphasises similarities between fashion and language systems and explores the effect of comparisons between grammar and fashion, as well as associated play activities, on the learning process. This article gives a few examples of visual metaphors used for teaching different aspects of linguistics and explains how they work to facilitate the -learning process and to capture students' attention. Applied to linguistics, these empirical findings will hopefully provide inspiring examples and serve as models for exploring visual metaphors in the teaching of other disciplines.
\end{abstract}

Keywords: innovative materials; new teaching/learning models

\section{Introduction}

For at least a century, research in psychology has proven that human memory works better with the aid of pictures than with that of words or numbers (Ozick, 1989), and yet textbooks for higher education rarely provide pictures to illustrate difficult concepts. Linguistics textbooks practically never do so. Fortunately, PowerPoint presentations allow teachers to bring images to the classroom, thus making the process of instruction and learning both more engaging and more memorable. In my teaching practice, I have developed a format that not only uses separate images but that also combines them into rather elaborate visual metaphors to help illustrate and explain complex linguistic concepts.

My interest in metaphor and ludolinguistics (Mollica, 2010) is rooted in my education in a school of fine arts and in my experience teaching students of the "Net Generation" (Tapscott, 1998). To understand my students better, I have often analysed my own learning experiences and come to the conclusion that the most memorable courses of my life were the ones in the art school. These courses differed from other classes in two key ways: there was a sense of aesthetic involved, and the classes were interactive. According to Don Tapscott, the new generation prefers interactive entertainment (video games and web surfing) to passive entertainment (television). My teaching experience confirms that our students prefer interactive exercises and enjoy playing games or matching pictures with concepts. But do they in fact learn the grammar better when I use visual metaphors, games, and give them interactive and creative exercises as homework?

In this article I will briefly describe my own experience of using visual metaphors in French linguistics courses. The main goal of this undertaking is to encourage teachers in higher education to use metaphors by showing that a little extra work is worth the effort here. My secondary objective is to contribute to the discussion about the use of PowerPoint in the classroom by forwarding a few arguments in its favour.

\section{Methods}

The methods used for the evaluation of the effect of visual metaphors on students' understanding and memory include specific questions added to customary course evaluations, 
simple surveys, and an analysis of students' success on tests and, especially, on quizzes designed specifically to check the understanding of the concept explained.

The creation of metaphors themselves technically requires only basic skills in working with PowerPoint presentations, mainly copy-paste or enlarge-minimize, as well as the ability to search the Internet and choose pictures that lend themselves to being combined into complex images. By way of basic advice for the choice of pictures: high-resolution images with a good colour contrast usually prove the best.

\section{Results and Discussion}

The importance of visual representations became apparent to me when I began working as a lecturer of French after the completion of my thesis on the process of denomination in fashion terminology. While participating in teaching and learning seminars, I was taken by by the idea of incorporating research into teaching, but linguistic material seemed too complicated to present to students in a general language course. Thus I had the idea of using fashion concepts and pictures to illustrate grammatical notions. To my own surprise, this process worked extremely well: not only did the students show greater interest in grammar; they also seemed to better comprehend it when I employed fashion illustrations as metaphors for style or syntactic structures. Later on, these metaphors proved invaluable for the teaching of linguistics.

\section{Fashion metaphors in the presentation of language structure}

To define the object of study in a linguistics course - Phonology, Morphology, or Syntax - it is necessary to give students an idea about its place within the field of study. It is not difficult to describe language studies in words, but outlining the whole picture of the discipline takes time if a teacher uses comprehensive examples, and it can become boring and insufficient if, on the other hand, a teacher does not take the time to provide proper examples for claims. Comparing language and fashion as two semiotic systems can prove quite convenient for the first presentation of the course. I, for example, use pictures representing clothing and linguistic terms to describe the branches of linguistic science.

The slide below (Figure 1) introduces the object of study in the course FREB45, French Morphology and Syntax, and requires only a brief explanation and appeal to students' imagination to compare the two systems: just imagine that the sounds of the languagephonemes-represent fabric; then we can from that cut out significant parts of words, morphemes, which, in turn, can be put together into words, just like items of clothing are sewn together. The words can subsequently form phrases and sentences, just like clothing items will constitute an outfit, and phrases can be organised into a speech, just like costumes can be assorted for a show. These few words, accompanied by pictures gradually appearing on the screen, suffice to introduce the course and give a clear image of its place within linguistics: morphology and syntax occupy its very core and help examine the structure of its main units, words and sentences.

Fashion pictures prove even more illustrative for the representation of stylistic levels of speech. 


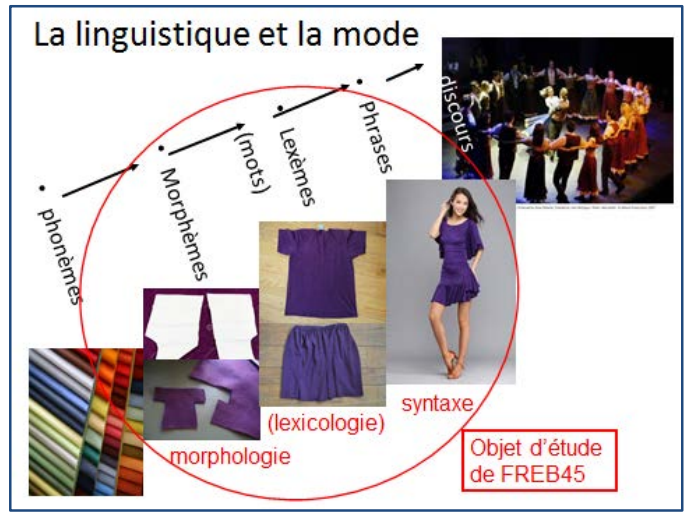

Figure 1. Branches of linguistic science

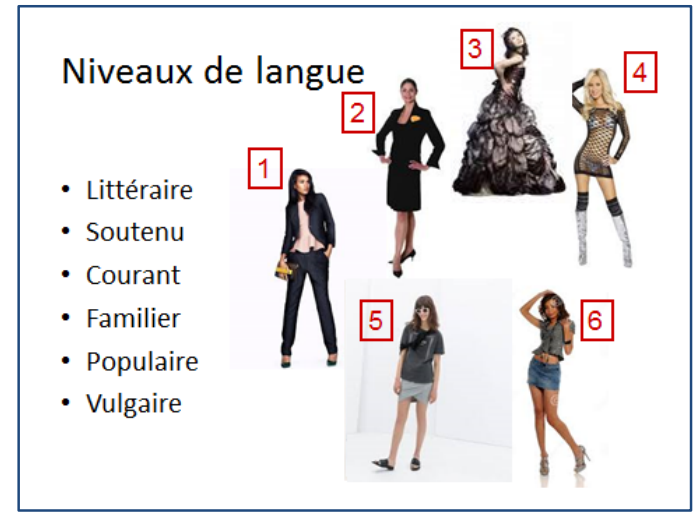

Figure 2. Stylistic levels in language and clothing

The comparison in Figure 2 also offers an opportunity for an interactive activity: I ask students to match the styles of language with the styles of clothing in the pictures. It helps engage them, explains the new terminology, and teaches a few things about French culture, because the activity inevitably leads to a short discussion about French fashion and European dress habits.

Once the comparison between language and fashion has been established, the metaphorical associations can be continued in a kind of semiotic game: each group of students is given the task of finding a correlation in style-literary, formal, regular, informal, low-key, and vulgarin all language and fashion components: pronunciation and the choice of fabrics; the choice of words and the selection of clothing items; the careful or careless matching of words and garments. The game provides a lot of fun and creates vivid memories about the correspondences. Students later even reported that-well beyond giving them a better understanding of levels of language - the comparison made them more aware of their habits of both language and dress.

\section{Fashion metaphors in the presentation of word structure}

In morphology, it is usually trickier to explain the linguistic terminology used to discern the structure of complex words than to teach the analysis of the structure itself. The distinction between the root (racine) and the stem (radical) somehow does not embed itself in students' minds easily. In my experience, they kept confusing the terms until I came up with a seemingly natural way to represent them through images of actual vegetable roots and stems, as in Figure 3.

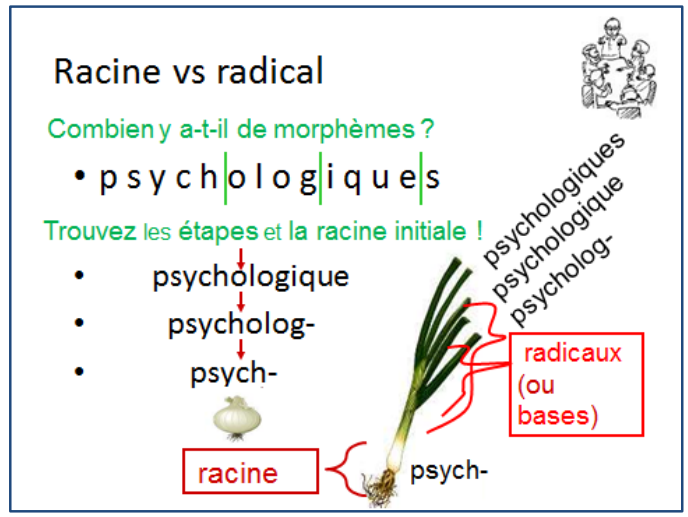

Figure 3. Root (racine) and stem (radical)

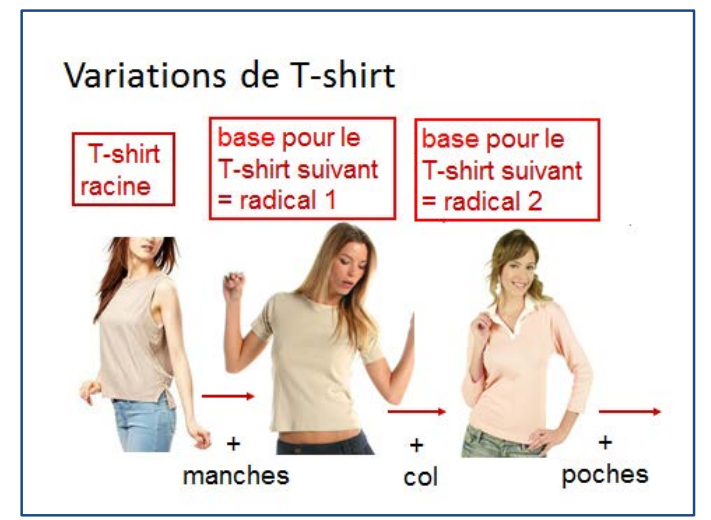

Figure 4. Root (racine) and stem (radical) in fashion 
However, some students particularly interested in fashion asked for a clothing analogy, and for the review, I had to come up with a new image (Figure 4), which helped to explain the concept further.

The root would be an item's initial, basic structure: on the one hand, it cannot be simplified without being destroyed; on the other, many further elements can be added to it-which transforms the original item, though it recognizably remains the main element in all garments of the same type. In the same way, the root of a word is the initial part that cannot be divvied up further and that can be recognized in all words built on it.

On the test I gave on the topic, students made no mistakes in the use of the terms, displayed a good understanding of the matter in most term definitions, and generally succeeded in identifying the root of complex words correctly.

\section{Fashion metaphors in the presentation of phrase structure}

The study of syntax provides even more opportunities to create metaphors and activities that use images of fashion. It is usually considered sufficient to simply provide examples (Figure 5) to illustrate the notion of verbal valence-a verb's capacity to take arguments (subject and complements), called thematic roles or $\theta$-roles in linguistics.

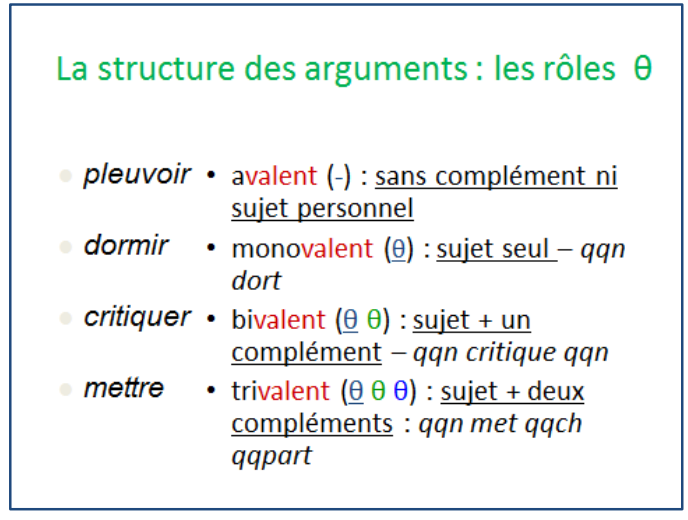

Figure 5. French examples for verbal valence

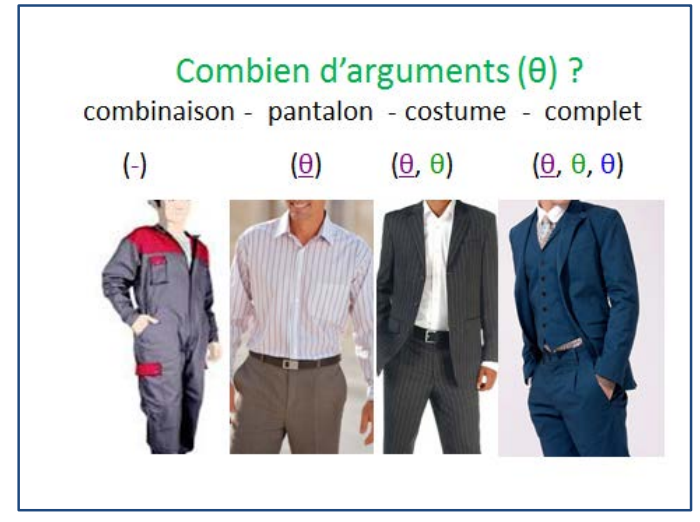

Figure 6. Fashion examples illustrating verbal valence

Yet students tend just to learn the examples without realising the conceptual importance of valence-it forms part of verbal meaning, of its nature, and verbs can be divided into classes according to this important characteristic. In the past, I used the chemical concept of valence as an explanation, but my efforts helped only those who had studied chemistry before, while tending to complicate things even more for those who had not.

Fashion metaphors (Figure 6) work for everyone and provide the groundwork for an interactive task: match a verb to a garment according to the number of $\theta$-roles it can accommodate. Verbs may require complementary items to fulfil their function in a phrase, just like articles of clothing may require other garments to constitute an outfit: a verb with a zero valence can be used by itself or with a purely grammatical subject (it rains), just like an overall is sufficient by itself; most verbs need a proper subject (somebody sleeps) to constitute the basis of a phrase, just like a pair of pants is usually complemented by at least a shirt. Many verbs take two arguments - a subject and a complement (somebody criticises something), just like suit pants demand both a shirt and a jacket. Quite a few verbs need to fill at least three $\theta$-roles to have a proper meaning (somebody puts something somewhere), just like a suit called complet in French always includes a vest besides the typical shirt and jacket. 
The interactive activity in class consists of assigning one of the pictures from the slide to each group of students, giving them a list of French verbs and asking them to identify all the verbs on the list that have the same number of $\theta$-roles as the clothing item on their picture. It makes the activity more fun than just choosing the verbs from the list, and, most important, it makes students understand that the verbs would not work without their arguments, just like some clothing items do not work without additional garments.

The same analogy helps explain that not all arguments of a verb (called "complementizers" in generative grammar) have an equal value: some of them are absolutely necessary, while others are optional, just like a T-shirt (Figure 8) seems like an absolutely necessary addition to the skirt, whereas a vest might complement these two garments or not. The slide in Figure 7 provides illustrations for a playful group activity to help distinguish compulsory and optional garments, after which students tend to follow the syntactic representation of compulsory and optional complementizers (Figure 8) with greater attention and interest.

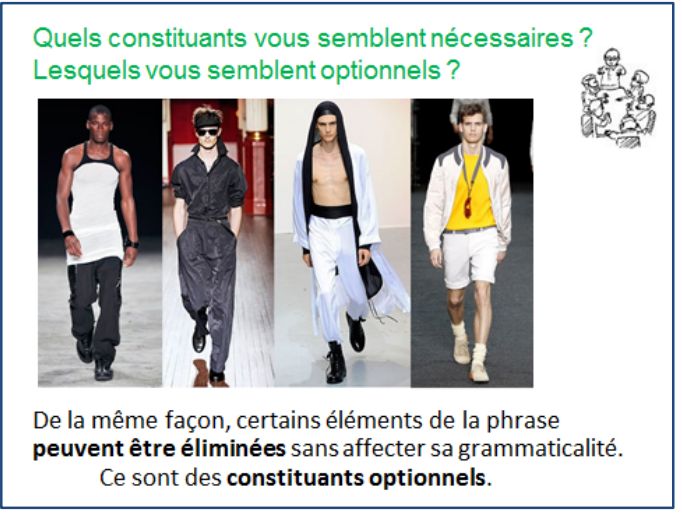

Figure 7. Optional and compulsory complementizers

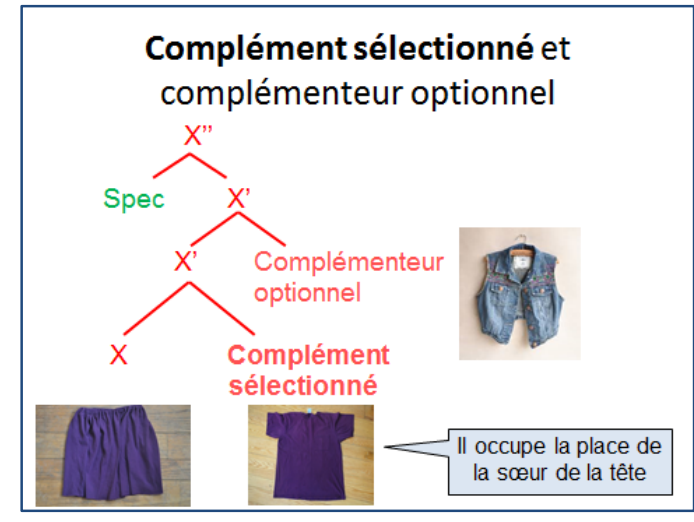

Figure 8. Complementizers in syntax and fashion

Fashion analogies provide a familiar element when we venture into representations of syntactic structures using syntactic trees and X-bar theory. We must convey to students that-despite their more complicated appearance with numerous symbols like $X^{\prime}$ and $X^{\prime \prime}-X$-bar representations actually simplify syntactic trees because they repeat the same structure over and over. In figure $9, \mathrm{X}$ is a variable replaced by $\mathrm{N}$ that stands for 'noun' to represent the structure of the noun phrase une jupe plissée (a pleated skirt) that includes one specifier and one complementizer - an article and an adjective/participle.

The picture of the same skirt in the middle of Figure 10 is associated with average length, and a description of this skirt provides an example of the most typical nominal phrase "a pleated skirt," where the noun "skirt" is used with a specifier, the article "a", and a complement, the adjective "pleated." Now this basic structure can be amplified with many complements of different natures, both in reality and in description- "a bicoloured, ankle-long pleated skirt," so that the corresponding syntactic tree gets longer, like the skirt on the picture. Yet the same basic structure $X$ ”- $X$ ' - X, in which the element " $X$ ' + Complement” is repeated several times, remains. In the same way, a skirt can be stripped of all its details, and the word "skirt" can be used without any specifiers or complements, as in a catalogue heading, for example. In its syntactic representation, however, we should still keep all three basic elements X”- X' - X, even if only to maintain the consistency of the representation. 


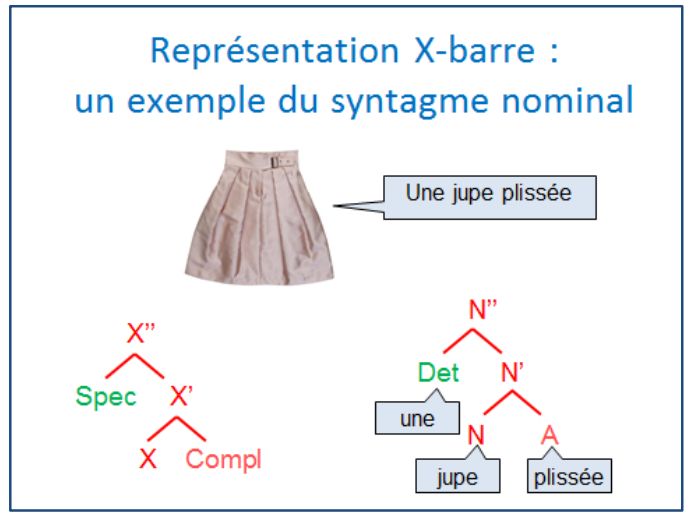

Figure 9. X-bar representation of a noun phrase trees

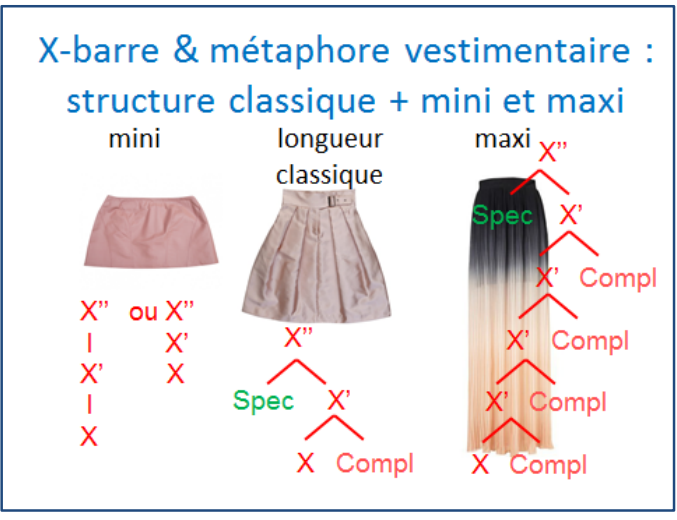

Figure 10. Fashion examples to explain syntactic

Many students reported that this analogy helped them remember to stick to the basic structure and to repeat it over and over when they switched from analysing to drawing syntactic trees. Once students manage to discern this basic structure in all trees, they experience a real breakthrough in their understanding of syntax.

\section{Conclusions}

Students greatly appreciate the comparisons described above. They become more attentive and participate more enthusiastically in class activities when fashion pictures are involved-this becomes obvious in class, and it is also reflected in their comments about fashion analogies in course evaluations. In 2014, out of 33 comments on course instruction, 16 mentioned the visual metaphors: 12 students found them helpful in understanding the concepts, 2 had mixed sentiments, and 2 more did not find them useful but fun nonetheless. In 2015, out of 19 comments, 12 were positive, 2 mixed, and none negative. Those who found the fashion metaphors helpful often mentioned their usefulness both in grasping the concept and in remembering it on a test.

The main significance of teaching through visual metaphors therefore lies in students understanding and remembering the material better. This improved comprehension clearly manifests in their tests and exams: the definitions of complex concepts explained with metaphors always exhibit a better understanding than even the ones that seemed simple enough to not require any illustration with pictures. Quizzes based on the activities comparing language and fashion practically display a 100 percent success rate, and students always remember the picture slides whenever I return to them during our review sessions.

In the ancient world, as Aristotle explains in Rhetoric, metaphor was praised as the greatest tool for the transmission of knowledge and thought. In modern times, the linguists George Lakoff and Mark Johnson have demonstrated the fundamental role of metaphor in language and mind (1975) as a mechanism allowing us to use what we already know from experience to understand numerous other subjects. The Internet provides almost limitless possibilities for finding images to illustrate any metaphorical analogy. Yet very little is written and done to promote this great teaching tool in higher education: for instance, in a recent volume on teaching linguistics, only 1 out of 18 chapters (Burridge, 2011) is dedicated to metaphors, and its excellent comparison of a language to a garden, penned by Kate Burridge, remains purely verbal. 
From my teaching experiments with fashion metaphors in linguistics, I have mainly derived encouragement to produce more visual analogies and to refine and develop the ones that have already proved useful. The project's implication for higher education in general is that instructors should use more visual representations and analogies in their classrooms and textbooks. In my own experience, I have found comparisons between fashion and language as two similar sign systems particularly useful. Fashion and clothing analogies appear appealing and understandable to all, and thus they might work just as well in other disciplines, much as the example in Figure 6 might be employed to explain the concept of valence in both linguistics and chemistry.

\section{References}

Aristotle. (1909). The Rhetoric (a translation by Sir Rchard Claverhouse Jebb; edited with an introduction and supplementary notes by John Edwin Sandys). Cambridge: Cambridge University Press.

Burridge, K. (2011). 'Two loaves where there seems to be one': metaphors we teach by. Teaching Linguistics: Reflections on Practice, K. Kuiper, ed. London: Equinox, 222-233.

Lakoff, G., \& M. Johnson. (1981). Metaphors We Live By. Chicago: University of Chicago Press.

Mollica. A, D. (2010). Ludolinguistica e glottodidattica. Toronto: Guerra-Soleil.

Ozick, C. (1989). Metaphor and Memory. New York: Knopf.

Tapscott, D. (1998). Growing Up Digital: The Rise of the Net Generation. New York: McGraw-Hill. 